Volume 8. No. 10, October 2020

International Journal of Emerging Trends in Engineering Research

Available Online at http://www.warse.org/IJETER/static/pdf/file/ijeter1128102020.pdf

https://doi.org/10.30534/ijeter/2020/1128102020

\title{
The Method of Increasing the Accuracy of Determining the Objects Coordinates in Radars through the Using of Information from Automatic Dependent Surveillance-Broadcast
}

\author{
Hennadii Khudov' ${ }^{1}$, Andrii Fedorov ${ }^{2}$, Oleh Lavrov ${ }^{3}$, \\ Oleh Aristarkhov ${ }^{4}$, Galina Misiyuk ${ }^{5}$, Irina Khizhnyak ${ }^{6}$ \\ ${ }^{1}$ Department of Radar Troops Tactic, Ivan Kozhedub Kharkiv National Air Force University, Kharkiv, Ukraine, \\ 2345kh_hg@ukr.net \\ ${ }^{2}$ Department of Radar Troops Tactic, Ivan Kozhedub Kharkiv National Air Force University, Kharkiv, Ukraine, \\ a.fedorov21@ukr.net \\ ${ }^{3}$ Air Force Scientific Center, Ivan Kozhedub Kharkiv National Air Force University, Kharkiv, Ukraine, \\ lavrov1107@gmail.com \\ ${ }^{4}$ The Technical Support Department, Ivan Cherniakhovskyi National Defence University, Kyiv, Ukraine, \\ 2345kh_hg@ukr.net \\ ${ }^{5}$ Department of Radar Troops Tactic, Ivan Kozhedub Kharkiv National Air Force University, Ukraine, \\ misiyuk@ukr.net \\ ${ }^{6}$ Department of Mathematical and Software Automated Control Systems, Ivan Kozhedub Kharkiv National Air \\ Force University, Kharkiv, Ukraine, khizh_ia@ukr.net
}

\begin{abstract}
The subject of study in the paper is to increase the accuracy of determining the coordinates of objects through the use of information ADS-B. Improving accuracy is achieved, inter alia, by adjusting the radar station. The aim is to develop a method of adjusting the radar station using the technology of automatic dependent monitoring ADS-B. Tasks: analysis of known methods of radar alignment, analysis of factors influencing the accuracy of determining the coordinates of air objects, brief analysis of the capabilities of ADS-B technology, development of a method of radar alignment using ADS-B technology. The methods used are: radar methods, methods for determining the coordinates of air objects, methods of mathematical analysis and differential calculus, methods of probability theory and mathematical statistics. The following results were obtained. The main disadvantages of the known methods of alignment of the radar are identified. Factors influencing the accuracy of determining the coordinates of air objects have been identified. The possibility of using the technology of automatic dependent observation to increase the accuracy of determining the coordinates of air objects has been established. A method of adjusting the radar using ADS-B technology has been developed. The main advantages of the proposed method of alignment are determined. The scientific novelty of the results is as follows. Improving the accuracy of alignment of the radar is achieved through the using of ADS-B technology. The advantages of using the
\end{abstract}

proposed method of adjusting the radar are simplification of the alignment process, determination of corrections without removing the radar station from normal operation, the possibility of using as control objects air objects equipped with ADS-B transponders and located in the detection zone of the radar station.

Key words: the method, accuracy, object coordinate, radar, ADS-B, GPS, transponder.

\section{INTRODUCTION}

The requirements for the accuracy of measuring the coordinates of air objects in the radar of the air traffic control system are becoming more stringent every year [1]-[5]. This is due to an increase in air traffic density. The requirements for the accuracy of measuring the height have especially increased due to the decrease in the width of the echelons to two or three hundred meters, and accordingly to the accuracy of measuring the elevation angle [5].

For surveillance radars, both en-route and aerodrome, the required measurement accuracy of the elevation coordinate increases to units of arc minutes at ranges of 300-400 km [5]-[18]. Practically similar accuracy can be provided only by single-pulse measurement methods [5].

The possibilities of the existing radar (for example, Figure 1, Figure 2, Figure 3) means for the implementation of radar control and the issuance of radar information with increased requirements for the accuracy of determining the coordinates of the software are somewhat limited. 
This is due to a number of reasons: radars are exposed to wind loads, weather, icing, temperature and humidity, there is mechanical wear of parts of antenna-rotary devices of locators, which leads to loss of accuracy of coordinate measurement [5]-[8], [16].

It is known [5], [17]-[19] that the accuracy of determining the coordinates of the software is influenced by several factors:

- tactical and technical characteristics of the radar (width of the radiation pattern, signal-to-noise ratio, etc.);

- weather conditions;

- terrain;

- instrumental errors of the radar (inaccuracy of the antenna orientation, operator errors in the visual removal of the azimuth of the targets;

- high-quality carrying out of regular and timely adjustment of radar.

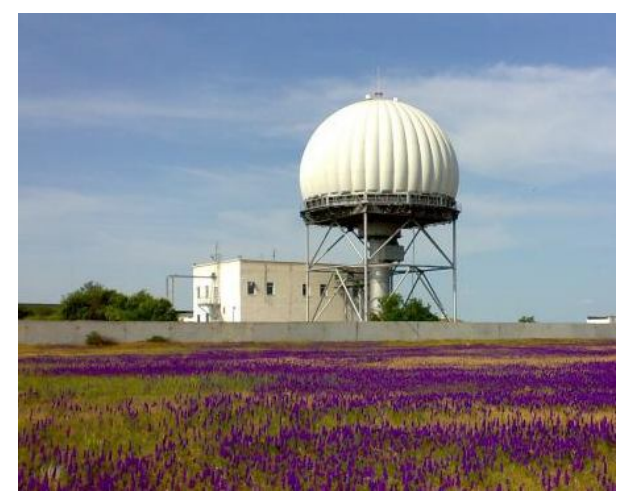

Figure 1. Radar "Skala-2M" (Ukraine)

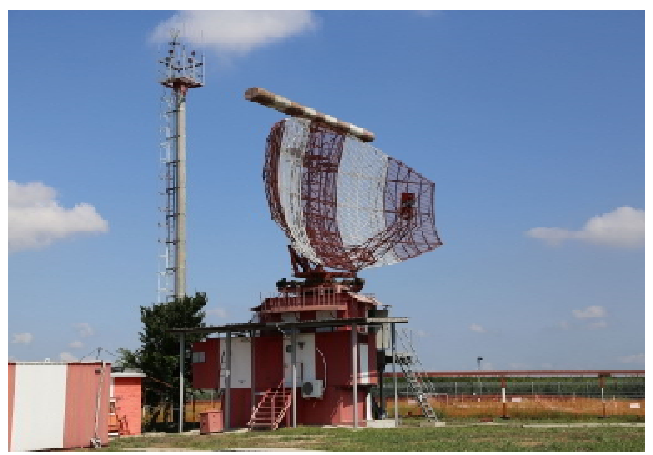

Figure 2. Radar "Irtysh" (Russia)

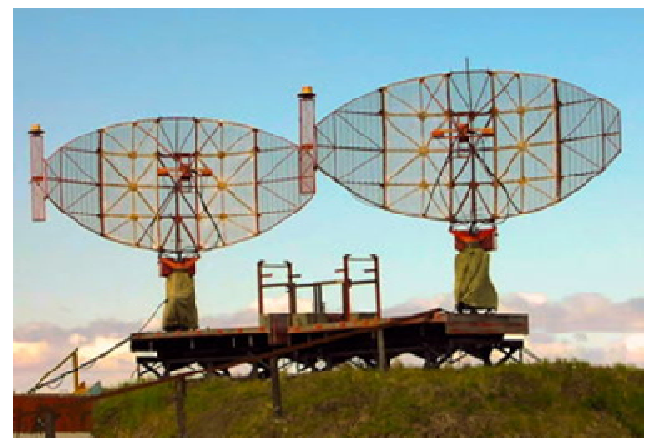

Figure 3. Radar 1L118 "Lira-1" (Ukraine)
In order to increase the accuracy of determining the coordinates of the software, consider the method of adjusting the radar.

\section{PROBLEM ANALYSIS}

At present, several methods of radar alignment are known [5], [19]-[20]. The first, by using reflected signals from objects whose positions (coordinates) are precisely defined.

Secondly, through the use of local objects, the position of which is determined by optical or geodetic means. However, this requires the presence of separately located objects that reflect the sounding signal or specially installed on the towers of reflectors or radiators, which requires high costs.

Third, the radio emission of the sun or other celestial bodies, which requires considerable time for its implementation and certain weather conditions.

Fourth, you can use aerial objects with precisely measured coordinates. The disadvantage of this method is the impossibility of proper alignment in cases where the coordinates of the radar being adjusted are determined with errors.

In modern conditions, the key role in the implementation of air traffic control is played by technologies based on global navigation satellite systems and the latest electronic surveillance systems [5].

It is now possible to obtain coordinates using the system of automatic dependent observation (ADS-B), by which the coordinates of the software are determined by the transponder ADS-B located on board the software, the signal with the coordinates of the software is emitted into space and received by appropriate receivers. The accuracy of determining the coordinates of the software using the system of independent cooperative surveillance (ADS-B) is 3-5 times higher than that of conventional radars [20]-[25].

Therefore, the coordinates obtained from the ADS-B system can be considered as reference coordinates, with which you can align the radar.

The purpose of the paper is to develop a method of adjusting the radar using the technology of automatic dependent monitoring.

\section{MAin MATeriaL}

The alignment of radar with the help of flying objects consists in determining and evaluating the differences $\Delta$ between the parameters of the experimental trajectory of the flying object, obtained by the adjusted means, and the 
Hennadii Khudov et al., International Journal of Emerging Trends in Engineering Research, 8(10), October 2020, 7353 - 7362

corresponding parameters of the reference trajectory of the same flying object (1).

$$
\Delta=\mathrm{L}_{\text {ref }}-\mathrm{L}_{\mathrm{Radar}},
$$

where $\mathrm{L}_{\text {ref }}-$ the reference trajectory of the flying object; $\mathrm{L}_{\text {Radar }}$ is the parameters of the experimental trajectory of the flying objects.

After definition and evaluation differences, they are as adjustment corrections must be entered into the functional software of the radar for the current correction of measurements.

Automatic dependent surveillance (ADS-B) is a cooperative surveillance technology in which an air object determines its location via a satellite navigation system and distributes it by an onboard transponder (Figure 4) [20]-[25].

This information can be received by ground stations of air traffic control units, as well as other aircraft, which allows crews to be more situationally aware.

ADS-B - "automatic" - because it operates without the intervention of the crew. "Dependent" - because it depends on the data of the aircraft's navigation systems.

In fact, ADS-B is an element of the "S" mode of the secondary surveillance radar system for air traffic control RBS (Radar Beacon System) [20]-[25].
ADS-B technology, which consists of two different services, "ADS-B Out" and "ADS-B In", can be used as an additional source of air traffic monitoring [20]-[25].

"ADS-B Out" through the on-board transmitter disseminates information about the exact location, altitude and speed of the air object, as well as other data from on-board software systems.

"ADS-B In" receives information from the channels FIS-B (flight information service) and TIS-B (Information about other traffic), as well as other ADS-B data, such as direct communication from an air object that is nearby.

A large amount of data is transmitted in ADS-B. These are, in particular, the values of altitude, speed and course, the values of vertical speed, the mode code "A" of the RBS system (so-called SQUAWK), the ICAO address (transmitted in each message), the call sign (Callsign). To solve the problem of alignment radars are of interest to the coordinates of the air object in the coordinate system WGS-84 (transmitted 2 times per second). These data are emitted with different discreteness from 0.5 seconds to 10 seconds [20]-[25].

Parameters of the self-generated signal ADS-B [20]-[25]:

- the standard signal length of the mode $S$, which is transmitted for detection, is 56 bits;

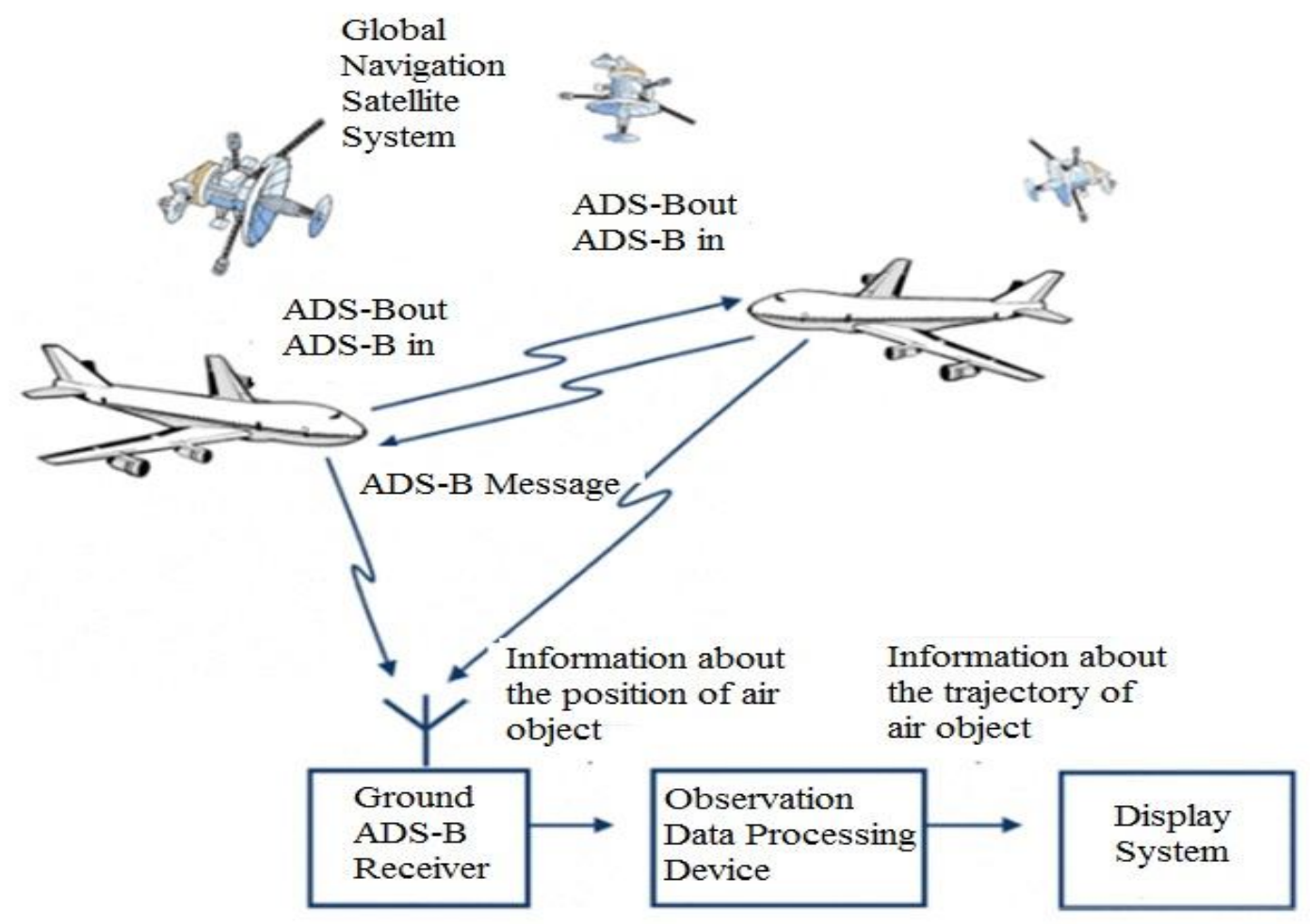

Figure 4. ADS-B system architecture for surveillance in the interests of air traffic services 
- signal $1090 \mathrm{MHz}$ ES includes an additional 56-bit data block with information ADS-B;

- the length of each ES message is $120 \mu$ s $(8 \mu$ s preamble, 112 $\mu$ data);

- signal transmission frequency $1090 \mathrm{MHz}$

- signal transmission speed of $1 \mathrm{Mbit} / \mathrm{s}$;

- data on the location of the air object is transmitted 2 times per second, the identification index - every 5 seconds.

Figure 5 shows a typical example of a Mode-S package consisting of two separate parts: a preamble followed by a data block.

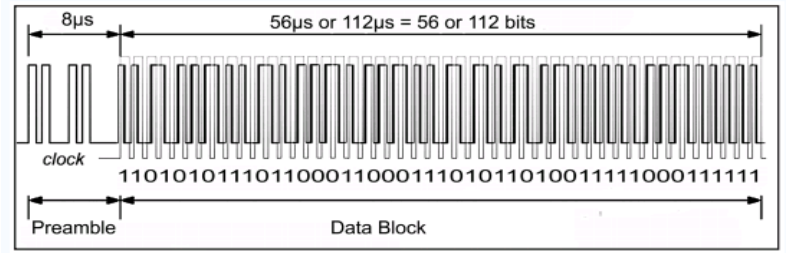

Figure 5. ADS-B signal packet structure

The preamble is used to "wake up" the request receiver and the decoder and consists of 4 pulses, each lasting $0.5 \mu \mathrm{s}$. The data block consists of 56 or 112 bits of general information 56 or $112 \mu \mathrm{s}$.

It should be noted that not all, even modern air objects are equipped with ADS-B transponders. Most Soviet-made aircraft do not have such equipment. But now almost all air objects have the ability to work in "S" mode of the secondary location system RBS.

In the secondary location mode, air objects respond to the request signals of route air traffic control locators. The response is performed at the same frequency as the ADS-B, namely $1090 \mathrm{MHz}$. Accordingly, the ADS-B receiver is able to receive signals of responses of air objects to the requests of route locators. And since air objects almost always fly in the field of route locators, there are almost always response signals [20]-[25].

The layout of the adjustable radars and air objects from which the information comes is presented in Figure 2.

Consider the essence of the method of adjusting the radar using the technology of automatic dependent monitoring.

The algorithm that implements the method of adjusting the radar using the technology of automatic dependent monitoring is as follows. At the first stage the orientation on the terrain of the adjusted radar is carried out.

In the second stage, the radar is adjusted by one of the known methods. One of the most common methods of adjusting the radar is adjusting with the help of an auxiliary radar. The essence of the method is that in the process of alignment determine the differences $\Delta \mathrm{x}, \Delta \mathrm{y}$ between the rectangular coordinates of the air object, measured by two radars. The obtained values of discrepancies are used to determine the errors of alignment (correction) of the radar being adjusted. When adjusting a particular radar, the second radar is auxiliary and must be adjusted in advance.

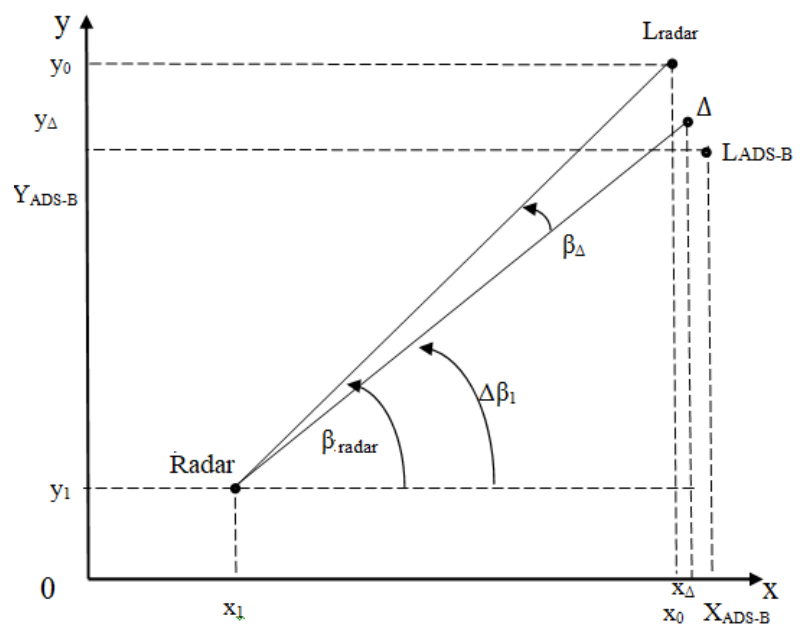

Figure 6. The layout of the adjustable radar and the air object from which the information comes

The methods assume the absence of errors of the auxiliary radar in azimuth and range to the air object. If the alignment of the auxiliary radar contains errors, the alignment of the radar that is being adjusted will also contain additional errors, which is a significant drawback.

With the help of satellite navigators determine the rectangular coordinates of the radar station $\left(\mathrm{x}_{0}, \mathrm{y}_{0}\right)$.

In the third stage, the adjustable radar measures the rectangular coordinates of the air object. Airspace survey is performed, for example, by circular rotation of the antenna and known methods of detection and determination of coordinates, which are embedded in the algorithm of a particular radar.

In the fourth stage, the coordinates of the current location of the air object are determined using the ADS-B receiver ( $\mathrm{x}_{\mathrm{ADS}-\mathrm{B}}$, $\left.\mathrm{y}_{\text {ADS-B }}\right)$. .

Cheap and small radios are used to receive ADS-B data from the air object.

The coordinates of the software are determined by onboard GPS navigators and emitted into space. The terrestrial receivers of the ADS-B system receive the corresponding messages at a frequency of $1090 \mathrm{MHz}$, which contain a large amount of data and, in particular, information about the current coordinates of the software, which are then used to align the radar.

In the fifth stage, the received rectangular coordinates are interpolated to a single point in time, mathematically 
Hennadii Khudov et al., International Journal of Emerging Trends in Engineering Research, 8(10), October 2020, 7353 - 7360

averaging the obtained rectangular coordinates of the software by expressions (2), (3):

$$
\begin{aligned}
\mathrm{x}_{\mathrm{MC}} & =\frac{\mathrm{x}_{0}+\mathrm{x}_{\mathrm{ADS}-\mathrm{B}}}{2}, \\
\mathrm{y}_{\mathrm{MC}} & =\frac{\mathrm{y}_{0}+\mathrm{y}_{\mathrm{ADS}-\mathrm{B}}}{2} .
\end{aligned}
$$

In the next step, the adjustments for the adjusted radar are calculated using expressions (4), (5).

$$
\begin{gathered}
\Delta \beta=\operatorname{arctg} \\
\frac{\mathrm{y}_{0}-\mathrm{y}_{\mathrm{n}}}{\mathrm{x}_{0}-\mathrm{x}_{\mathrm{n}}}-\operatorname{arctg} \frac{\mathrm{y}_{M C}-\mathrm{y}_{\mathrm{n}}}{\mathrm{x}_{M C}-\mathrm{x}_{\mathrm{n}}}, \\
\Delta \mathrm{D}=\sqrt{\left(\mathrm{x}_{\mathrm{MC}}-\mathrm{x}_{\mathrm{n}}\right)^{2}+\left(\mathrm{y}_{M C}-\mathrm{y}_{\mathrm{n}}\right)^{2}}- \\
-\sqrt{\left(\mathrm{x}_{0}-\mathrm{x}_{\mathrm{n}}\right)^{2}+\left(\mathrm{y}_{0}-\mathrm{y}_{\mathrm{n}}\right)^{2}}
\end{gathered}
$$

In the seventh stage, the calculated adjustments are compared with the resolution of the radar that is being adjusted, and if the adjustments are greater than the resolution of the radar that is being adjusted, the settings of this radar are changed. Measurements and calculations are repeated until the magnitude of the corrections is less than the resolution of the adjustable radars.

\section{CONCLUSION}

The main advantages of the proposed method of radar alignment are simplification of the alignment process, determination of corrections without removing the radar from normal operation, the possibility of using as control objects air objects flying in the detection zone of the radar and equipped with ADS-B transponders.

In addition, the adjustment can be performed automatically, correcting errors arising from wind loads and temperature fluctuations.

The use of the method can significantly reduce the time for its implementation, which is especially important in conditions of limited time.

advantages of the proposed method for synchronizing the ADS-B receiver system when maintaining radar control of air environment using MLAT technology is the ability to use as control objects random AO flying in the area of responsibility of the radar units and equipped with ADS-B transponders. In addition, synchronization can be performed automatically. The adjustment can be conducted at certain intervals. Using this method can significantly increase the accuracy of synchronization, which will provide a more accurate determination of the coordinates of an $\mathrm{AO}$, even if the $\mathrm{AO}$ is not appointed with the appropriate ADS-B equipment.

As a result, the following achievements were obtained. The factors affecting the accuracy of determining the coordinates of $\mathrm{AO}$ are determined. The possibility of using the automatic dependent surveillance - broadcast technology and multilateration technology to improve the accuracy of determining the coordinates of $\mathrm{AO}$ is established. It was estimated that for the qualitative determination of the $\mathrm{AO}$ coordinates, it is necessary to ensure the accuracy of receiver synchronization less than $1 \mu \mathrm{s}$. A method of synchronizing ADS-B receivers when maintaining radar control of air environment using MLAT technology has been developed, which ensures the necessary synchronization accuracy. An algorithm that implements the synchronization method of the ADS-B receiver system using multilateration technology is proposed.

The scheme of diagnostics in the automated system of technical diagnostics for a case of complex use of energy-static, energy-dynamic and electromagnetic methods is resulted. The order of complex use of energy-static, energy-dynamic and electromagnetic methods of diagnosis is given.

The direction of further research is the practical application of the developed method for synchronizing the ADS-B receiver system using multilateration technology.

\section{REFERENCES}

1. ICAO Doc. 9574. Manual on implementation of a $300 \mathrm{~m}$ (1 $000 \mathrm{ft})$ vertical separation minimum between FL 290 and FL 410 inclusive. International Civil Aviation Organization, 2001. $44 \mathrm{p}$.

2. ICAO Doc. 8168 OPS/611. Aircraft operations. Vol. 1. Flight procedures. International Civil Aviation Organization, 2006. 279 p.

3. ICAO Doc. 8168 OPS/611. Aircraft operations. Vol. 2. Construction of visual and instrument flight procedures. International Civil Aviation Organization, 2006. $701 \mathrm{p}$

4. M. Bromfield, T. Walton, and D. Wright, Evaluation of Low-Cost Solutions to Support Flight Operations Quality Assurance, Journal of Air Transportation, 2020, Vol. 28, № 1, pp. 15-22.

5. G. Profatilova, G. Solov'ev, V. Efremov, A. Solov'ev, Adjusting Goniometer System Parameters in a Monopulse Surveillance Radar Station. Vestn. Mosk. Gos. Tekh. Univ. im. N.E. Baumana, Priborostr. [Herald of the Bauman Moscow State Tech. Univ., Instrum. Eng.], 2017, № 6, $\quad$ P. 64-75. 10.18698/0236-3933-2017-6-64-75

6. I. Ruban, H. Khudov, V. Lishchenko, A. Zvonko, S. Glukhov, I. Khizhnyak, V. Maliuha, Y.Polonskyi, R. Kushpeta The Calculating Effectiveness Increasing of Detecting Air Objects by Combining Surveillance Radars into The Coherent System, International Journal of Emerging Trends in Engineering Research, Vol. 8. № 4, 2020, pp. 1295-1301 DOI: https://doi.org/10.30534/ijeter/2020/58842020.

7. V. Lishchenko, V. Chaliy, H. Khudov, and A. Zvonko. Proposals for Improving of Air Surveillance Informativity in MIMO Radar Systems Based on 
Hennadii Khudov et al., International Journal of Emerging Trends in Engineering Research, 8(10), October 2020, 7353 - 7360

Two-Dimensional Radars, in Intern. Scient.-Pract. Conf. Problems of Infocommunications. Science and Technology (PIC S\&T), 2018, pp. 153-156. DOI: https://doi.org/10.1109/infocommst.2018.8632052.

8. H. Khudov, S. Kovalevskyi, A. Irkha, V. Lishchenko, O. Serdiuk and F. Zots, The Proposals for Synchronization Positions of MIMO Radar System on the Basis of Surveillance Radars, in Intern. Scient.-Pract. Conf. Problems of Infocommunications. Science and Technology (PICS\&T), 2019, pp. 547-551. DOI: https://doi.org/10.1109/PICST47496.2019.9061284.

9. M. Iasechko, M. Mozhaiev, I. Manzhai, M. Volk, V. Manoylo, O. Ochkurenko, D. Maksuita, V. Larin, A. Markov, and O. Kostyria. Conditions for Reliable Transmission of Information Over Long Distances Using a Powerful Electromagnetic Radiation, IJATCSE. $\quad 8(1), \quad 2020, \quad$ pp. 138-144. DOI: https://doi.org/10.30534/ijeter/2020/18812020.

10. H. Khudov, A. Zvonko, I. Khizhnyak, V. Shulezko, V. Khlopiachyi, V. Chepurnyi, and I. Yuzova. The Synthesis of the Optimal Decision Rule for Detecting an Object in a Joint Search and Detection of Objects by the Criterion of Maximum Likelihood, International Journal of Emerging Trends in Engineering Research, № 8(2), 2020, pp. 520-524. DOI: https://doi.org/10.30534/ijeter/2020/40822020.

11. H. Khudov, I. Khizhnyak, V. Koval, V. Maliuha, A. Zvonko, V. Yunda, V. Nagachevskyi, and V. Berezanskyi The Efficiency Estimation Method of Joint Search and Detection of Objects for Surveillance Technical Systems, International Journal of Emerging Trends in Engineering Research, Vol. 8. № 3, 2020, pp. 813-819.

DOI: https://doi.org/10.30534/ijeter/2020/34832020.

12. V. Lishchenko, H. Khudov, V. Tiutiunnyk, V._Kuprii, F.ZZots, and G._Misiyuk. The Method of Increasing the Detection Range of Unmanned Aerial Vehicles In Multiradar Systems Based on Surveillance Radars, in 2019 IEEE 39th International Conference on Electronics and Nanotechnology (ELNANO), 2019. DOI: https://doi.org/10.1109/ELNANO.2019.8783263.

13. H. Khudov, I. Khizhnyak, I. Yuzova, O. Baranik, G. Semiv, S. Bondarenko, and O. Tytarenko. The Optimization Technique for Joint Discrete Search and Detection of Observation Objects, International Journal of Emerging Trends in Engineering Research, № 8(2), 2020, pp. 533-538. DOI: https://doi.org/10.30534/ijeter/2020/42822020.

14. H. Khudov, I. Khizhnyak, F. Zots, G. Misiyuk, and O. Serdiuk. The Bayes Rule of Decision Making in Joint Optimization of Search and Detection of Objects in Technical Systems, International Journal of Emerging Trends in Engineering Research, № 8(1), 2020, pp.

$7-12$. DOI: https://doi.org/10.30534/ijeter/2020/02812020.
15. G. V. Khudov, Features of optimization of two-alternative decisions by joint search and detection of objects. Problemy Upravleniya I Informatiki (Avtomatika), 2003, № 5, pp. 51-59.

16. H. Khudov V. Lishchenko, A. Irkha, and O. Serdjuk, The method of the high accuracy finding $2 \mathrm{D}$ coordinates in MIMO-radar based on existing surveillance radars, 2019 International Conference on Information and Telecommunication Technologies and Radio Electronics, UkrMiCo 2019, Odessa, Ukraine, 2019, pp. 1-4, doi: 10.1109/UkrMiCo47782.2019. 9165319.

17. M. Iasechko, M. Kolmykov, V. Larin, S. Bazilo, H. Lyashenko, P. Kravchenko, N. Polianova, and I. Sharapa Criteria for performing breakthroughs in the holes of radio electronic means under the influence of electromagnetic radiation, ARPN Journal of Engineering and Applied Sciences, Vol. 15. № 12, 2020, pp. 1380-1384.

18. M. Iasechko, N. Sachaniuk-Kavets'ka, V. Kostrytsia, V. Nikitchenko, and S. Iasechko The results of simulation of the process of occurrence of damages to the semiconductor elements under the influence of the multi-frequency signals of short duration, Journal of Critical Reviews, Vol. 7. № 12, 2020, pp. 109-112. DOI: https://doi.org/10.31838/icr.07.13.18.

19. V. Gertzman, A. Vaintraub, A. Ekalo, and K. Zinoviev, Method of increasing the accuracy of alignment of radar stations via low-orbiting spacecrafts, Izvestii Saint Petersburg Electrotechnical University "LETI", № 9, 2017, P. 21-27.

20. V. Sukhov, and V. Savvateyev, Sposob yustirovki radiolokatsionnykh stantsiy sistemy avtomaticheskogo upravleniya. Patent №2030759, Rossiyskaya Federatsiya. 2012148572/07, Zayavl. 15.11.2012. Opubl. 10.09.14.

21. H. Khudov, A. Zvonko, S. Kovalevskyi, V. Lishchenko, and F. Zots. Method for the detection of smallsized air objects by observational radars, Eastern-European Journal of Enterprise Technologies, № 2/9 (92), 2018, pp. 61-68.

DOI: https://doi.org/10.15587/1729-4061.2018.126509.

22. H. Khudov, A. Fedorov, D. Holovniak, and G. Misiyuk. Improving the Efficiency of Radar Control of Airspace with the Multilateration System Use, in Intern. Scient.-Pract. Conf. Problems of Infocommunications. Science and Technology (PIC S\&T), 2018, pp. 680-684. DOI: https://doi.org/10.1109/infocommst.2018.8632141.

23. H. Khudov, A. Fedorov, D. Holovniak, and G. Misiyuk, Method of Radar Adjustment with Automatic Dependent Surveillance Technology Use, in Intern. Scient.-Pract. Conf. Problems of Infocommunications. Science and Technology (PIC S\&T), 2019, pp. 402-406. DOI:https://doi.org/10.1109/PICST47496.2019.9061245

24. H. Khudov, S. Glukhov, O. Maistrenko, A. Fedorov, A. Andriienko, and O. Koplik, The Method of ADS-B Receiver Systems Synchronization Using MLAT Technologies in the Course of Radar Control of Air 
Hennadii Khudov et al., International Journal of Emerging Trends in Engineering Research, 8(10), October 2020, 7353 - 7360

Environment, International Journal of Emerging Trends in Engineering Research, Vol. 8. № 5, 2020, pp. 1946-1951.

DOI: https://doi.org/10.30534/ijeter/2020/78852020.

25. Flightradar 24.

URL: https:// https://www.flightradar24.com/apps. 13 October 2020).

(accessed 